\title{
A First Approach to Design Mobility Function and Noise Filter in VLC System Utilizing Low-cost Analog Circuits
}

\author{
https://doi.org/10.3991/ijes.v5i2.6700 \\ Syifaul Fuada \\ Institut Teknologi Bandung (ITB), Bandung City, West Java, Indonesia \\ syifaulfuada@pme.itb.ac.id \\ Angga Pratama Putra \\ Institut Teknologi Bandung (ITB), Bandung City, West Java, Indonesia \\ anggapratap@gmail.com \\ Yulian Aska \\ Institut Teknologi Bandung (ITB), Bandung City, West Java, Indonesia \\ yulian.yulianaska@gmail.com \\ Trio Adiono \\ Institut Teknologi Bandung (ITB), Bandung City, West Java, Indonesia \\ tadiono@stei.itb.ac.id
}

\begin{abstract}
Visible Light Communication (VLC) as one of wireless technology must be able to offer a good capability as mobile communication system. The signal will be faded when the distance and angle of LED to photo-detector become higher at a certain distance. Other problem at VLC system is light interference noise which is caused by flicker effect from other light sources such as incandescent, fluorescent, DC-lamp (i.e. flashlight) and the sunlight. Each of lights have specific carried signal characteristics and it can influences the VLC system. In this paper we offer design of mobile VLC system based on analog domain. We use Automatic Gain Controller (AGC) circuit using commercially available IC and it will be placed at analog front-end receiver side. AGC can self-adjust its gain according to the input signal amplitude. We also design ana$\log$ filter to eliminate all interferences noise spectrum which is existed under 50 $\mathrm{KHz}$. We design both circuits, analog filter and AGC in VLC receiver system with low-cost. The test data are obtained through the simulation and achieved good results in ideal condition.
\end{abstract}

Keywords-Automatic gain controller (AGC), Ambient light noise, Mobility system, Noise interference filtering, Visible light communication (VLC)

\section{$1 \quad$ Introduction}

Visible light communication (VLC) technology is worthed to be developed and explored further, because this communication technology serves several advantages. 
VLC is different with other optical wireless communications (OWC) such as laser and infra-red. VLC use visible light as medium, therefore it can be utilized by light emitting diode (LED) as transmitter devices. Moreover, LED also became popular lighting device which is commercially used today. This make VLC technology has good potential for market targets.

During the light propagates in the free space, the signal information which is carried by light source became attenuated, and suffer with interference noise as well as ambient light noise. The signal attenuation is caused by irregular light distribution in a room. Light intensity received by photo-detector is strongly influenced by the distance between photo-detector and LED. Similar with other wireless communication technology (e.g. radio frequency) which serves mobility function, VLC is proper to adopt this function that can be used for larger field-of-view (FOV).

Many researchers have addressed mobility problem, e.g. demonstrated by Y. Hong \& L-K. Chen [1], using digital domain, they are using a specific algorithm and it can be moving from $30 \mathrm{~cm}$ to $50 \mathrm{~cm}$. Then proposed by $\mathrm{C}-\mathrm{H}$. Yeh et. al. [2] which is approached at analog domain, this research is using automatic gain control (AGC) at receiver-side and it can be used with 1.5 meters of free channel distance. The AGC circuit can be developed by utilizing commercially available integrated circuits components (analog or digital IC) also self-development by using specific configuration [3]. And mixed approach, digital and analog domain, is demonstrated by S. Deng et al. [4], actually this research is only for light sensing application. However, based on their experiment, it is shown that signal output at analog receiver can be stabilized by microcontroller. It is possible to implement for light communication such as VLC. Also W. Han et. al [5] use mixed methods, hardware and software, to build AGC for $\mathrm{RF}$ communication to reduce high PAPR signal in OFDM. This proposed design can be adapted in VLC system.

One of many serious challenges in VLC is other light source interference. In indoor application main interference source comes from fluorescent with electronic ballast or conventional ballast as well as incandescent (bulb) which can creates noise because its flickering effect is sharing the same band. Then LED lamp, flashlight as well as sunlight also create ambient light. These interferences can significantly influence the VLC performance.

In our previous research, we propose solution to reduce these noise by using analog filters (Sallen-key high pass filter \& twin-T notch filter) placed in receiver-side with specific cut-off frequency [6]. This designed filter perform well both for analog modulation and digital modulation, interference signal became attenuated and can improve BER, even though it only use commercially available component. C.H. Yeh et. al. design RC-low pass filter and $1^{\text {st }}$ order high pass filter which is applied at transmitter side for improving LED bandwidth and validated by Arbitrary Waveform Generator (AWG) [7]. And W. Song et. al. use coupling capacitor to block the DC signal (generated by ambient light) then amplifying end signal by amplifier circuit [8]. Y. Zao \& Vonkulbhisal use adaptive minimum voltage cancellation to improve immunity characteristic from sunlight. Verified test is done by transfering digital signal at near window location [9] and this circuit is designed for OOK modulation. L. Grobe et. al. perform VLC system based PAM-FDM modulation in which analog filter used both 
at transmitter-side to split AC-signals and DC-bias used for modulation and receiverside for removing DC signal due to interference from noise, incandescent light and natural light [10].

Both, light noise and attenuated signal information are two problems in the optical wireless communication which are different issues. In this paper, we try to propose a VLC system which can solve these problem in one solution. We use analog domain approach at receiver-side of VLC platform in order to design noise-filter circuit and AGC circuit that is customizable and low-cost.

\section{Methodology}

\section{$2.1 \quad$ VLC Link}

From the channel characteristic, visible light communication system can be divided into two parts, line-of-sight (LOS) and non-LOS. For high-speed application, as well or high-mobility VLC, LOS channel is more recommended. It is because receiver faced directly to the transmitter, as illustrated on Fig. 1a using single LED and photodiode. On non-LOS configuration, the light reflection characteristic from other object (e.g. mirror, wall) must be also considered.

Photodiode is usually used on the receiver system in the majority of high-speed VLC system. This device has some drawback in its limited FOV [11], so that a certain technique and configuration are needed to be able to use it on higher FOV. Another drawback is the internal capacitance $\left(C_{j}\right)$ factor of the photodiode [12] which can disturb the performance of the communication system. To broaded the FOV of the receiver system, we can use the multi-photodiode which configured to receive tha data in parallel (Fig. 1b) or adding more transmitter (Fig. 1c and Fig 1e). Also we can use the light reflection from a certain device as concentrator (Fig. 1d). In this research, we concentrate in designing the mobile system using single transmitter amd receiver as shown on the Fig. $1 \mathrm{f}$.

Then, in this part we also introduce a big VLC platform which is used as reference in designing the analog front-end circuit. Fig. 2 shows some block which can be divided into transmitter, channel and receiver. We use point to point communication from PC to PC. The original data is came from PC-A then processed using FPGA board, the architecture is discussed in [19]. To reduce the bit-error rate (BER), we use Viterbi decoder [20]. Then the information signal is transmitted through digital-toanalog converter (DAC) which connected into the LED driver circuit, as discussed in [21-23]. The signal is multiplexed using OFDM to modulate the signal using multicarrier modulation.

The data is transmitted through the LED and then received on the photodiode. The signal then amplified using pre-amplifier circuit. While the interference signal is filtered using high-pass filter and the sun light interference is blocked using capacitor. AGC circuit can be used to stabilize the output of the filter which varying because of the changing distance between transmitter and receiver. On the next stage, the output data of the AFE converted into digital using analog-to-digital converter (ADC) to 
sampling the data. The data the processed in digital using FPGA board before displayed on the PC-B and then compared with the transmitted data from PC-A.

The focus of this paper is on the analog-front end receiver using the simulation based approachment. The scope of the problem of this experiment is the type of filter which is specially used for the static condition. For the dynamic interference noise, multi-stage filter block is needed which made the circuit to become complex. Hybrid analog-digital filter is needed, this problem is an open research topic in designing the VLC system.

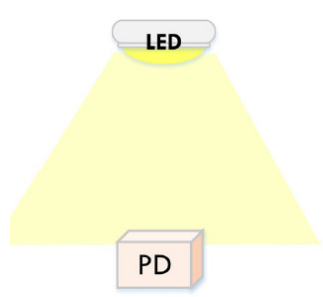

(a)

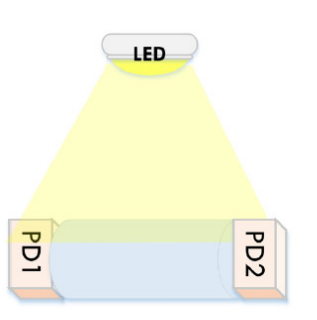

(d)

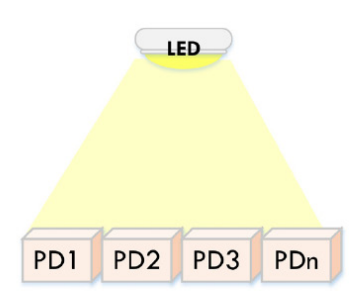

(b)

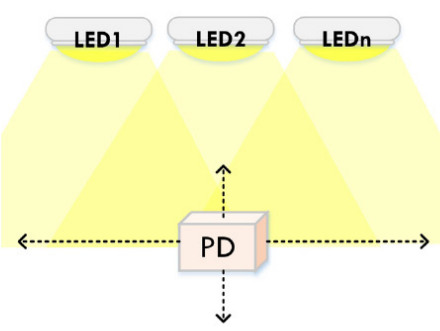

(e)

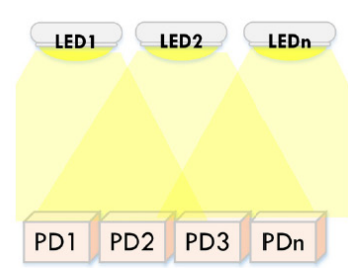

(c)

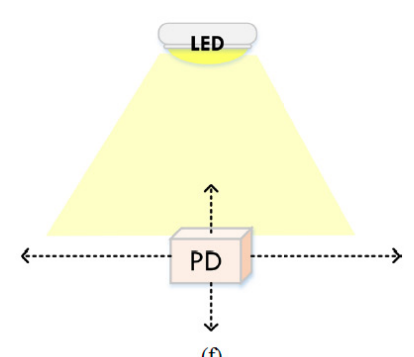

Fig. 1. Signal transferred through visible light with various scenarios: (a) Single transmitter and receiver in LOS configuration with fixed setting [13]; (b) fixed setting of single transmitter and array-photodiode to increase FOV [14]; (c) fixed setting of multitransmitter and multi-photodiode, generally used for MIMO VLC scheme [15]; (d) higher FOV with fixed setting method based double receiver and single transmitter using fluorescent concentrator which is proposed by [16]; (e) movable setting using multitransmitter and single photodiode, typically this configuration is used for indoor localization [17-18]; (f) single transmitter and single photodiode in movable receiver setting 


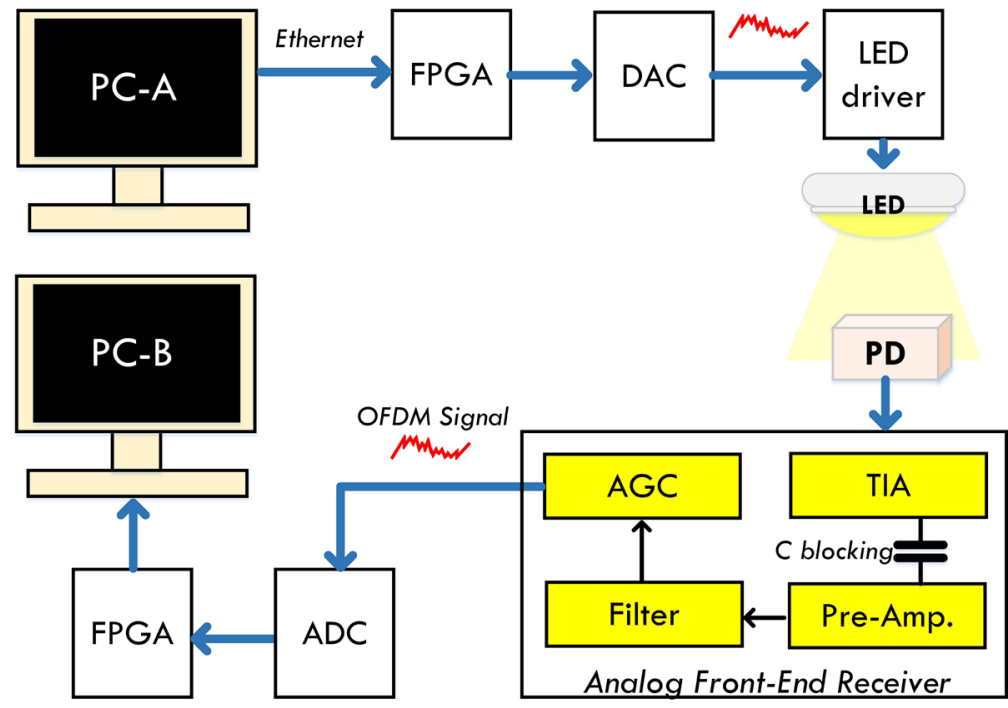

Fig. 2. Block diagram of VLC platform based OFDM used at indoor application. In this paper the focus is on analog front-end receiver, especially analog filter as ambient light noise cancelation and AGC circuit, they are indicated by the yellow boxes.

\subsection{Angular distribution of light based LOS channel}

Fig. 3a shows the LOS channel model in an indoor $3 \mathrm{~m} \times 3 \mathrm{~m} \times 3 \mathrm{~m}$ room, where the angular distribution of the radiation intensity pattern of LED is modeled using Lambertian light intensity model. Photodiode is modeled as active area $\left(A_{r}\right)$, which receiving the light radiation from the angle $\Psi$ which has smaller value than the FOV of the photodiode. DC gain for the photodiode reciver which placed at distance $d$ and receive angle $\theta$ toward transmitter is modeled using eq. 1 , so that the power received by the photodidode is as in eq. 2 , where $P_{t}$ is the transmitter power.

$$
\begin{aligned}
& \mathrm{H}_{\mathrm{los}}(0)=\left\{\begin{array}{r}
\frac{\mathrm{A}_{\mathrm{r}}\left(\mathrm{m}_{1}+1\right)}{2 \pi} \cos ^{\mathrm{m} 1}(\theta) \cos \Psi \\
\text { for } 0 \leq \Psi \leq \Psi_{\mathrm{c}}
\end{array}\right. \\
& \mathrm{P}_{\mathrm{r}-\text { loss }}=\mathrm{H}_{\text {los }}(0) \mathrm{P}_{\mathrm{t}}
\end{aligned}
$$

The result of the simulation using MATLAB is shown on Fig. 3b using 3D graph. Whereas, the top view (2D), is shown on Fig. 3c with parameters: LED power $=50$ watt; distance of single LED to single photodiode $=3$ meter, FOV $=30^{\circ}$; transmitter's semi-angle half-power $\left(\phi_{1 / 2}\right)=30^{\circ}$ and $A_{r}=5.8 \mathrm{~mm}^{2}$. The larger $d$ and FOV, the weaker the received power on photodiode. To stabilize the information signal on receiver from the varying $d$ and FOV, the AGC block is needed. 


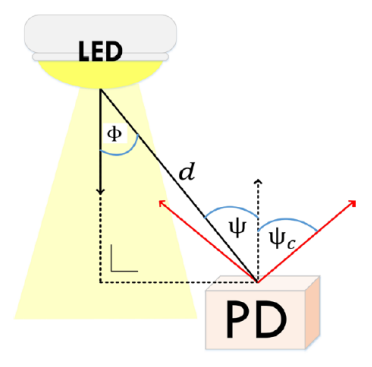

(a)

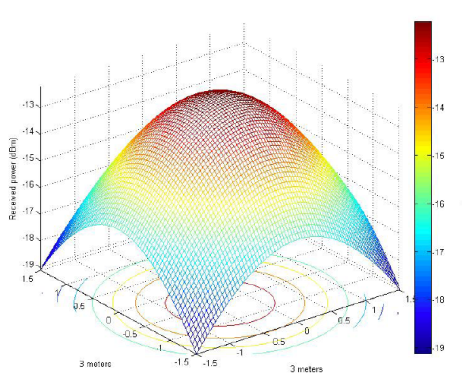

(b)

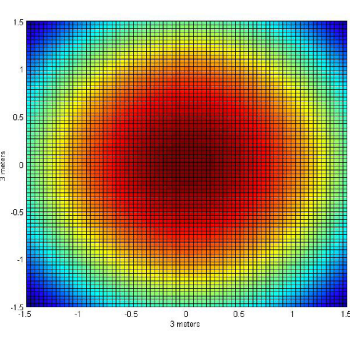

(c)

Fig. 3. (a) Geometry LOS channel configuration in indoor VLC system; (b) MATLAB simulation of light intensity distribution in room based 3D view; (c) $2 \mathrm{D}$ view with number of grid $=25$

\subsection{Analog front-end receiver proposed design}

The complete schematic of proposed analog receiver circuit design is shown in Fig. 4, these circuits are according to Fig. 2. The receiver circuit is consisted of Transimpedance Amplifier (TIA), analog filter and analog AGC using LM13700. All of the OP-AMP used in this design are products of Texas Instrument. Inc. Because this company provide a SPICE® circuit file of their product for majority, we can adapt our design requirement then run and compile its model in simulation. It really helps in the design process and saving time, effort and also cost in building circuit before real implementation. In other side, TI inc. also serves simulator tool such as TINA ${ }^{\mathrm{TM}}$. In this paper, the simulation is done by TINA-TI SPICE® simulation software version 9, which is free to be used and has all the feature needed as a circuit simulator tool.

For TIA, we use OPA 847, which is a wideband, ultra-low noise amplifier (LNA). It has typical high bandiwdth of maximum $3.9 \mathrm{Ghz}$ and high slew rate of $950 \mathrm{~V} / \mu \mathrm{s}$. According to datasheet, this $\mathrm{iC}$ is recommendd to be used in LNA and TIA application, so that it is compatible with VLC application. While, in the filter block, we use OPA 695 as OP AMP. This IC is an ultra-wideband amplifier with $1400 \mathrm{MHz}$ bandwidth and gain factor of 2 with low power characteristic of $129 \mathrm{~mW}$. Detail specification of each IC is shown on Table 1 where all IC are operating $\pm 5 \mathrm{~V}_{\mathrm{DC}}$, whereas the photodiode specification is shown on Table 2. 


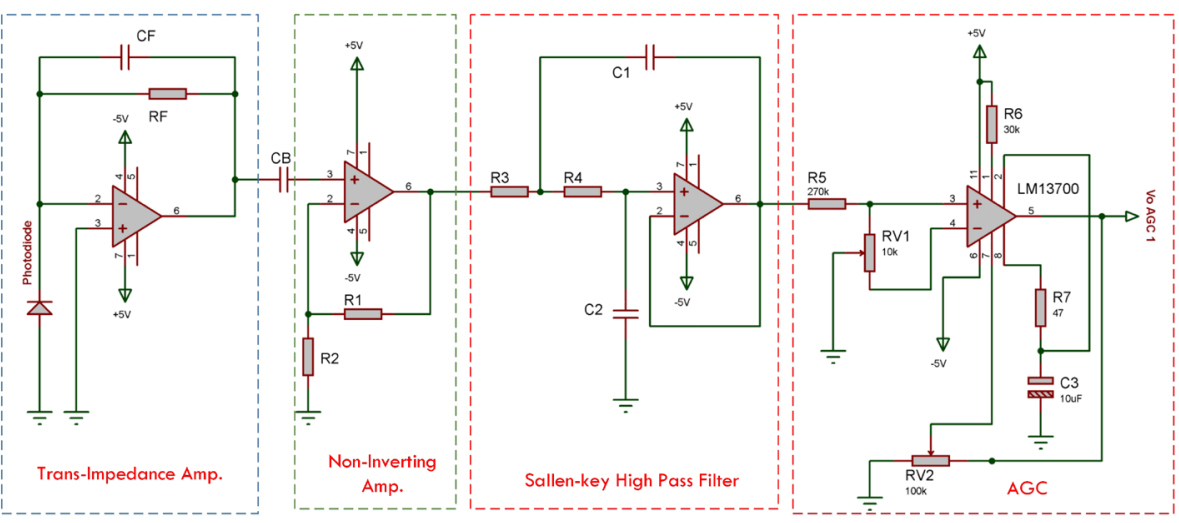

Fig. 4. Proposed analog front-end receiver circuit which will be applied in VLC system

Table 1. ICs specification

\begin{tabular}{rccclc}
\hline Model & Open loop gain & GBP & Input capacitance & \multicolumn{1}{c}{ Used as } & Cost \\
\hline OPA 847 & $88 \mathrm{~dB}$ & $3900 \mathrm{MHz}$ & $3.7 \mathrm{pF}$ & TIA & $\$ 3.32$ \\
\hline OPA 695 & - & $1700 \mathrm{MHz}$ & $1.2 \mathrm{pF}$ & Active filter & $\$ 1.40$ \\
\hline LM13700 & - & $3 \mathrm{MHz}$ & - & AGC & $\$ 0.94$ \\
\hline
\end{tabular}

Table 2. Photodiode specification

\begin{tabular}{cccccc}
\hline Model & Cj & Photosensitive area & Short circuit current & Rise time & Cost \\
\hline S1227-66BQ & $950 \mathrm{pF}$ & $5.8 \mathrm{~mm} \times 5.8 \mathrm{~mm}$ & $16 \mu \mathrm{A}$ & $2 \mu \mathrm{s}$ & $\$ 22$ \\
\hline
\end{tabular}

\subsection{Trans-impedance amplifier design}

The key elements for this design are the feedback resistors $\left(\mathrm{R}_{\mathrm{f}}\right)$ and feedback capacitors $\left(C_{f}\right)$ which is connected in parallel configuration, where $R_{f}$ function is to determine the gain of the amplifier and $\mathrm{C}_{\mathrm{f}}$ to reduce noise gain [24]. In this design, we use S1227-66BQ photodiode (PD) from HAMAMATSU which has bandwidth spectrum from UV to visible light. According to specification, this $\mathrm{PD}$ has $\mathrm{Cj}=950 \mathrm{pF}$ when operating in $10 \mathrm{KHz}$, switching time about $2 \mu \mathrm{s}$, generates $20 \mathrm{pA}$ dark current $\left(I_{R}\right)$, large photosensitive area $(5.8 \mathrm{~mm} \times 5.8 \mathrm{~mm})$ and short current $\left(\mathrm{I}_{\mathrm{sc}}\right)$ about $16 \mu \mathrm{A}$. The value of $R_{f}$ can be calculated by $R_{f}=V_{o} / I_{S C}$ and value of $C_{f}$ can be calculated by $\mathrm{Cf}=\operatorname{Sqrt}\left(\left(C_{j}+C_{i n}\right) / 2 \pi * R_{f} * f\right)$, where $f=1 \mathrm{MHz}$. While the saturated output voltage of amplifier targeted is $0.5 \mathrm{~V}_{\mathrm{DC}}$, then the resistor is given by $31.250 \Omega$ (available in market $=33 \mathrm{~K} \Omega$ ) and $\mathrm{C}_{\mathrm{f}}=67.8 \mathrm{pF}$ or $50 \mathrm{pF}$ as an available component which can be achieved from capacitor series connection of $100 \mathrm{pF}$.

The TIA circuit is configured as generic photovoltaic mode which has low noise characteristic. And the cut-off frequency of TIA is given by eq. 3 [25] where GBP is the amplifier gain bandwidth product and $\mathrm{C}_{d}$ is the sum of the junction capacitance $\left(\mathrm{C}_{\mathrm{j}}\right)$ of photodiode and amplifier capacitance $\left(\mathrm{C}_{\mathrm{in}}\right)$. 


$$
\mathrm{f}_{-3 \mathrm{~dB}}=\sqrt{\frac{\mathrm{GBP}}{4 \pi * \mathrm{R}_{\mathrm{f}} * \mathrm{C}_{\mathrm{d}}}}
$$

In TIA, there are three main sources of noise, i.e. $R_{f}$ noise $\left(\mathrm{N}_{\mathrm{Rf}}\right)$, current noise $\left(\mathrm{N}_{\text {current }}\right)$, and voltage noise $\left(\mathrm{N}_{\text {voltage }}\right)$. The total noise is the root-sum-square (RSS) which given by eq.4. The high band TIA design and its noise analysis are explained detail in [26-29]. Also, consideration for choosing commercial photodiode at LOS channel VLC is described in [11].

$$
\mathrm{N}_{\text {total }}=\sqrt{\mathrm{N}_{\text {Rf }}^{2}+\mathrm{N}_{\text {current }}^{2}+\mathrm{N}^{2} \text { OP-AMP's voltage }}
$$

\subsection{Non-inverting amplifier design}

Since output maximum of TIA is only $0.5 \mathrm{~V}_{\mathrm{DC}}$, hence amplifier circuit is needed. The output voltage of the TIA is connected into non-inverting amplifier circuit. Capacitor blocking $\left(\mathrm{C}_{\mathrm{b}}\right)$ is used to block the DC signal which is caused by the interference light from sun and flashlight [30]. In this case the ADC on the system needs input voltage of $\pm 1 \mathrm{~V}_{\mathrm{DC}}$, so the signal is amplified $4 \mathrm{x}$. The transfer function of this non-inverting amplifier is $A_{v}=1+\frac{R 1}{R 2}$, so if the value of R2 is chosen to be $1 \mathrm{~K} \Omega$, the value of $\mathrm{R} 1$ is $3 \mathrm{~K} \Omega$.

\subsection{Sallen-key High Pass Filter design}

In this research, we will design active filter to reduce interference signal and noise of LF fluorescent $(100 \mathrm{~Hz}), \mathrm{HF}$ fluorescent $(35 \mathrm{KHz})$, incandescent $(400 \mathrm{~Hz})$ [31], DC LED and also sunlight which carry the DC signal and $10 \mathrm{~Hz}$ frequency [32]. Based on these literature, Butterworth Sallen-Key configuration with $50 \mathrm{KHz}$ cut-off frequency will be used (maximum bandwidth target of VLC system is $1 \mathrm{MHz}$ ). We use Sallen-key topology, because this topology provides high value of Q but with simple configuration of component. The transfer function of this filter topology is as shown below,

$$
H(s)=\frac{s^{2}}{s^{2}+\frac{\omega_{0}}{Q} s+\omega_{0}^{2} s}
$$

Where,

$$
\begin{gathered}
\frac{\omega_{0}}{Q}=2 \pi\left(\frac{f_{c}}{Q}\right) s=2 \zeta \omega_{0} \\
\omega_{0}=2 \pi f_{c}=\frac{1}{2 \pi \sqrt{R_{3} R_{4} C_{1} C_{2}}} \\
\omega_{0}^{2}=\left(2 \pi f_{c}\right)^{2}
\end{gathered}
$$


Therefore,

$$
H(s)=\frac{s^{2}}{s^{2}+2 \zeta\left(2 \pi f_{c}\right) s+\left(2 \pi f_{c}\right)^{2} s}
$$

The cut-off frequency of this high pass filter is $f_{c}=50 \mathrm{KHz}$. To simplify the calculation of the design we set the value of $\mathrm{R} 3=\mathrm{R} 4=\mathrm{R}$ and $\mathrm{C} 1=\mathrm{C} 2=\mathrm{C}=100 \mathrm{pF}$, so the value of $R$ can be calculated using eq. 9 and then we obtain $R=33 \mathrm{~K} \Omega$.

$$
\mathrm{f}_{\mathrm{c}}=\frac{1}{2 \pi \mathrm{RC}} ; \mathrm{R}=\frac{1}{2 \pi \mathrm{f}_{\mathrm{c}} \mathrm{C}} ;
$$

In designing high pass filter we need to know the available bandwidth, it is really important beacuse if the available bandwidth is narrow but the band frequency is wide, the frequency can't be used to occupy all of the information. To be used in VLC system, the characterization of the interference and artificial lighting such as incandescent and fluorescent need to be known, using the spectrum analyzer. So that the filter design can be more specific because the noise profile has been characterized.

\subsection{Automatic Gain Controller (AGC) design}

The AGC system is included in other researches in order to accommodate movable receiver in distance, without changing the receiving signals amplitude. A. Böcker, et al using digital signal modulation and build AGC based recommendation of TL026C datasheet [33]. Then Angga Pradana use LM13700 as AGC circuit [32], according to this experiment, LM13700 can compensate the distance and angle change of light source. Other experiment beyond VLC application was done by G. Feng et. al that focus in HF communication using AD603 (low noise, 90MHz bandwidth) [34]. Developed AGC was successfuly tested and can work well.

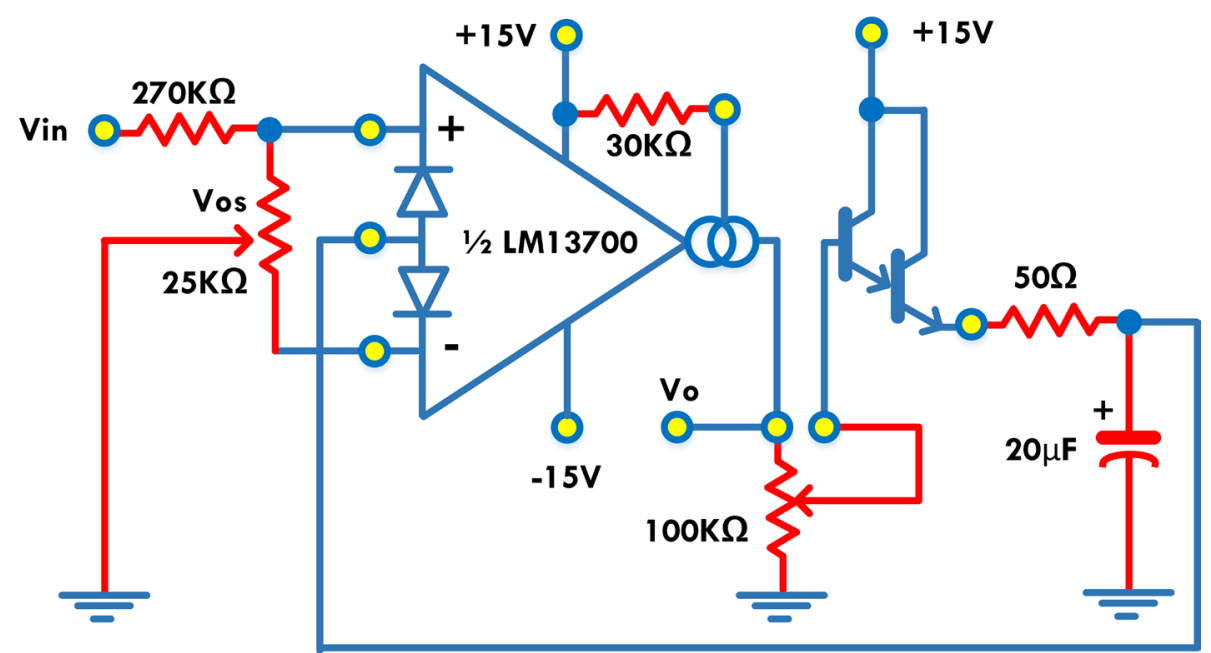

(a) 


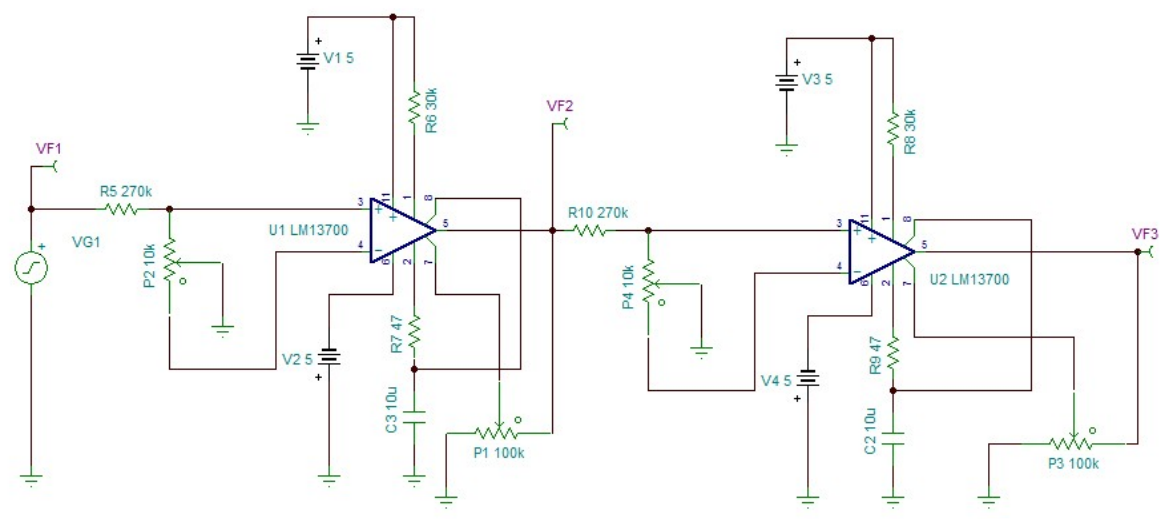

(b)

Fig. 5. AGC circuit: (a) configuration which is recommended from datasheet [35];

(b) experiment set up of double AGC LM13700 using TINA-TI SPICE®

In this research, we use discrete component IC LM13700 as AGC which is current controlled trans-conductance amplifier, differential input and push-pull output. The LM13700 detect the peak input voltage to dynamically control the output voltage within the required range. Fig. 5a shows the output signal from LM13700 buffer is feedback to the linier diode input diode linier. The Gain of LM13700 is controlled by the current flowing in the linier diode. If $\mathrm{V}_{\mathrm{o}}$ reach high amplitude $\left(3 \mathrm{~V}_{\mathrm{BE}}\right)$, it will trigger the Darlington transistor and linear diode. The increasing current in diode will reduce the gain, hence the $\mathrm{V}_{\mathrm{o}}$ can be maintained. Then, if applied in circuit, it will be shown as Fig. 5b. The LM13700 has two channels and in this design, we only use single channel $\left(\frac{1}{2}\right.$ LM13700).

\section{$3 \quad$ Result and Analysis}

\subsection{Simulation test}

TINA-TI SPICE® simulation schematic of the TIA is shown in Fig. 6, where Op. Amp. $=$ OPA 847; $\mathrm{Ct}=1.02 \mathrm{nF} ; \mathrm{R}_{\mathrm{f}}=33 \mathrm{~K} \Omega ; \mathrm{C}_{\mathrm{f}}=50 \mathrm{pF}$. TIA has cut-off frequency at $1.78 \mathrm{MHz}$ when $65 \mathrm{~dB}$. 

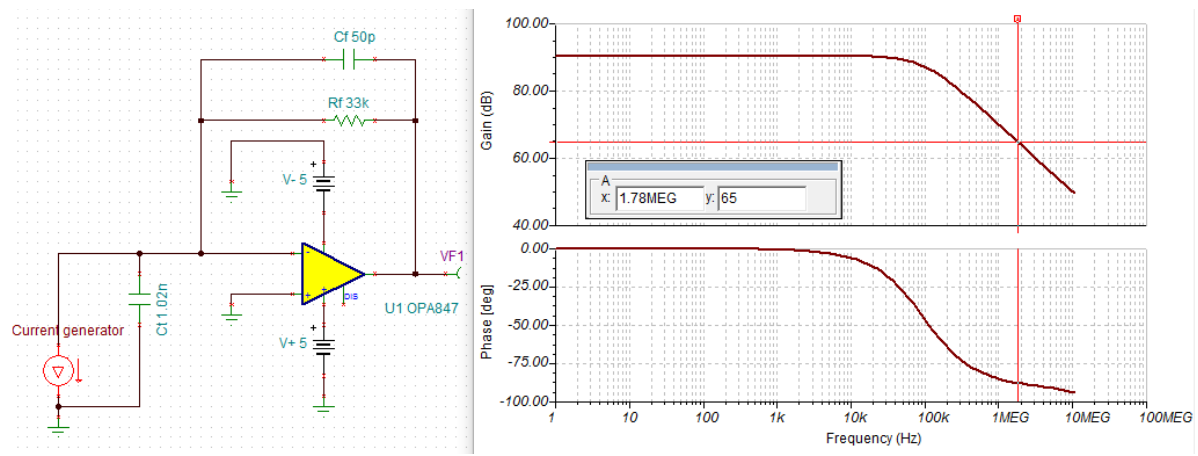

Fig. 6. TIA circuit and $a c$ transfer function using TINA-TI SPICE ${ }^{\circ}$

The schematic and simulation result of active filter design is shown in Fig. 7, where Op. Amp. $=$ OPA $847 ; \mathrm{C}=100 \mathrm{pF} ; \mathrm{R}_{\mathrm{f}}=33 \mathrm{~K} \Omega$. The sallen-key high pass filter has cut-off frequency at $50 \mathrm{KHz}$ when $-9 \mathrm{~dB}$.
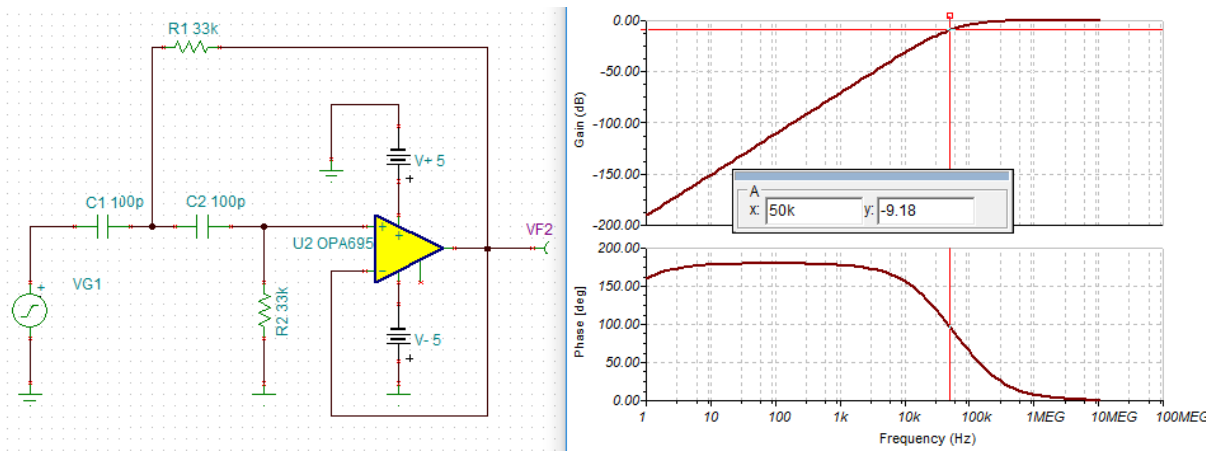

Fig. 7. Sallen-key high pass filter and $a c$ transfer function using TINA-TI SPICE®

Then, the simulation result of the AGC circuit is shown on Fig. 8, where the input signal is varied from $0 \mathrm{~V}$ to $10 \mathrm{~V}_{\mathrm{DC}}$, and Fig. 8 with small input signal amplitude from $0.1 \mathrm{~V}_{\mathrm{DC}}$ to $1 \mathrm{~V}_{\mathrm{DC}}$. Fig. 9 is the frequency response with component configuration based on Fig. 5a. Then the DC characteristic is simulated by using the 'Analysis' menu and choose the "DC analysis" then "DC transfer characteristic" feature. The result shows the output is stable at around $4 \mathrm{~V}_{\mathrm{DC}}$. The cut-off frequency $\left(\mathrm{f}_{-3 \mathrm{~dB}}\right)$ of this one stage AGC circuit is $2.76 \mathrm{MHz}$. The output voltage can become more stable using two stage AGC. This result shows that this configuration can be implemented for high-speed VLC, as well as giving the mobility characteristic into the system. Because the maximum input voltage of $A D C$ is $\pm 1 \mathrm{~V}_{\mathrm{DC}}$ or $2 \mathrm{~V}_{\mathrm{PP}}$, then the output of the AGC need to be weakened $2 \mathrm{x}$. To do this, the non-inverting amplifier is used before the circuit is connected into ADC board. But this is conditional, it depends on the result of the real experiment. 
Paper-A First Approach to Design Mobility Function and Noise Filter in VLC System Utilizing Low...

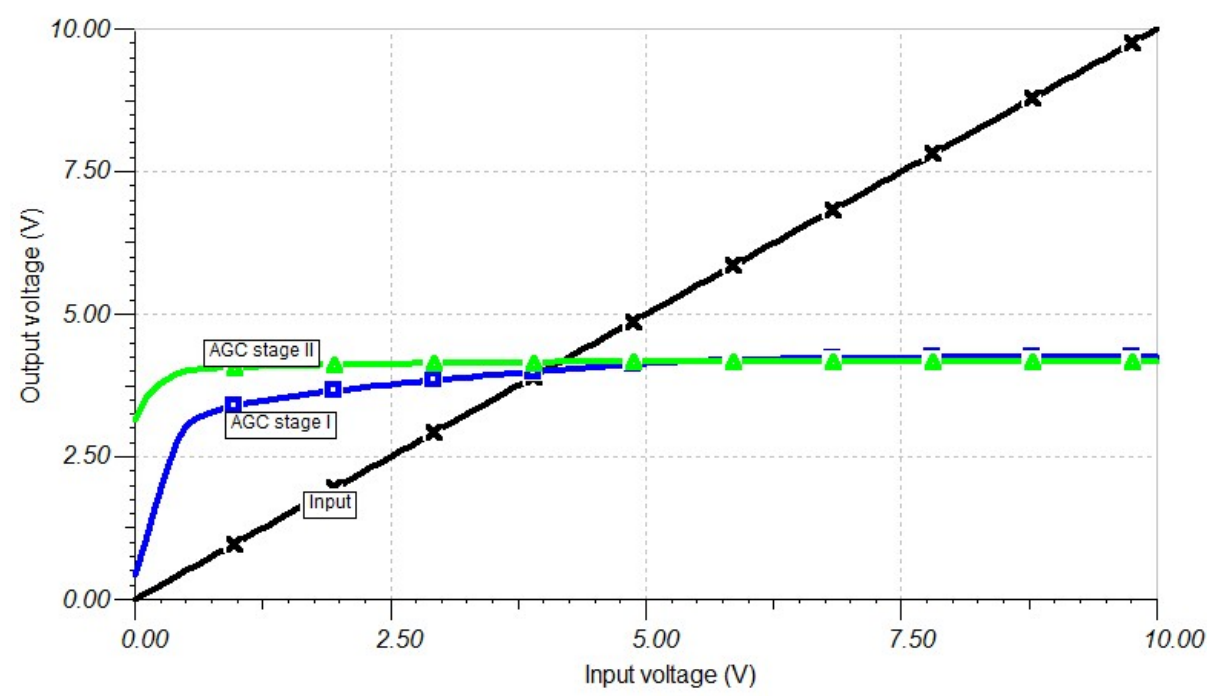

Fig. 8. DC signal characteristic of two stage AGC circuit using IC LM13700 from varied input voltage $1 \mathrm{VDC}$ to $10 \mathrm{VDC}$

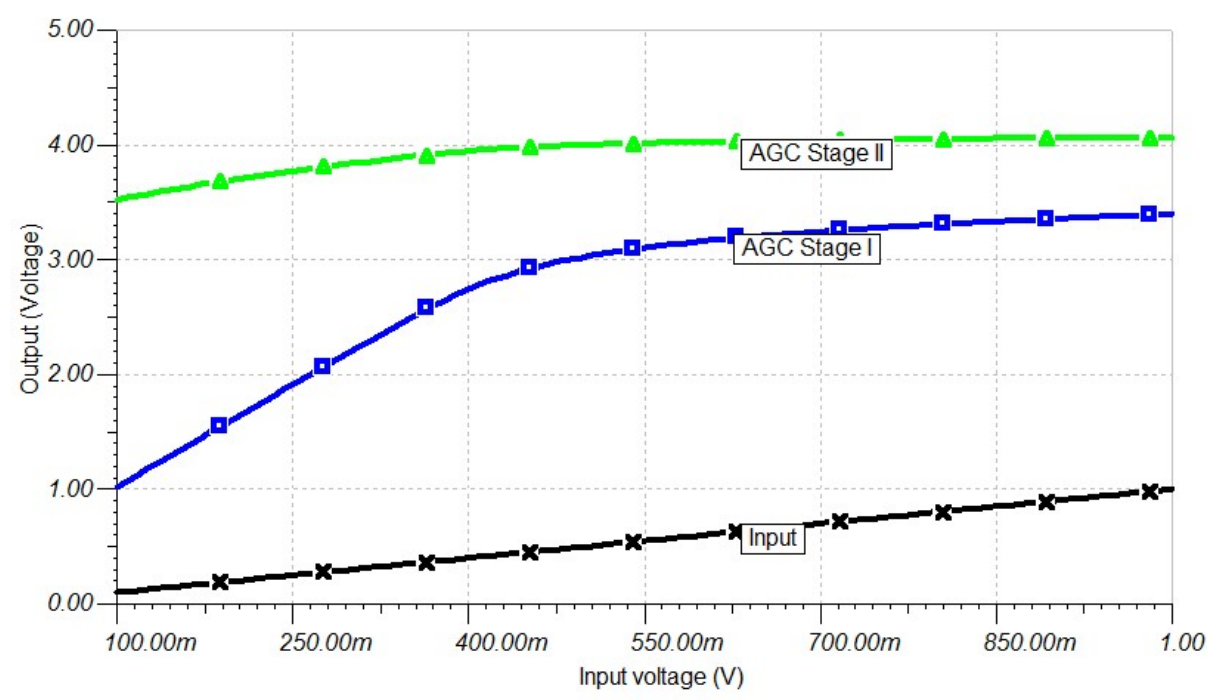

Fig. 9. DC signal characteristic of two stage AGC circuit using IC LM13700 from varied input voltage $0.1 \mathrm{~V}_{\mathrm{DC}}$ to $1 \mathrm{~V}_{\mathrm{DC}}$ 

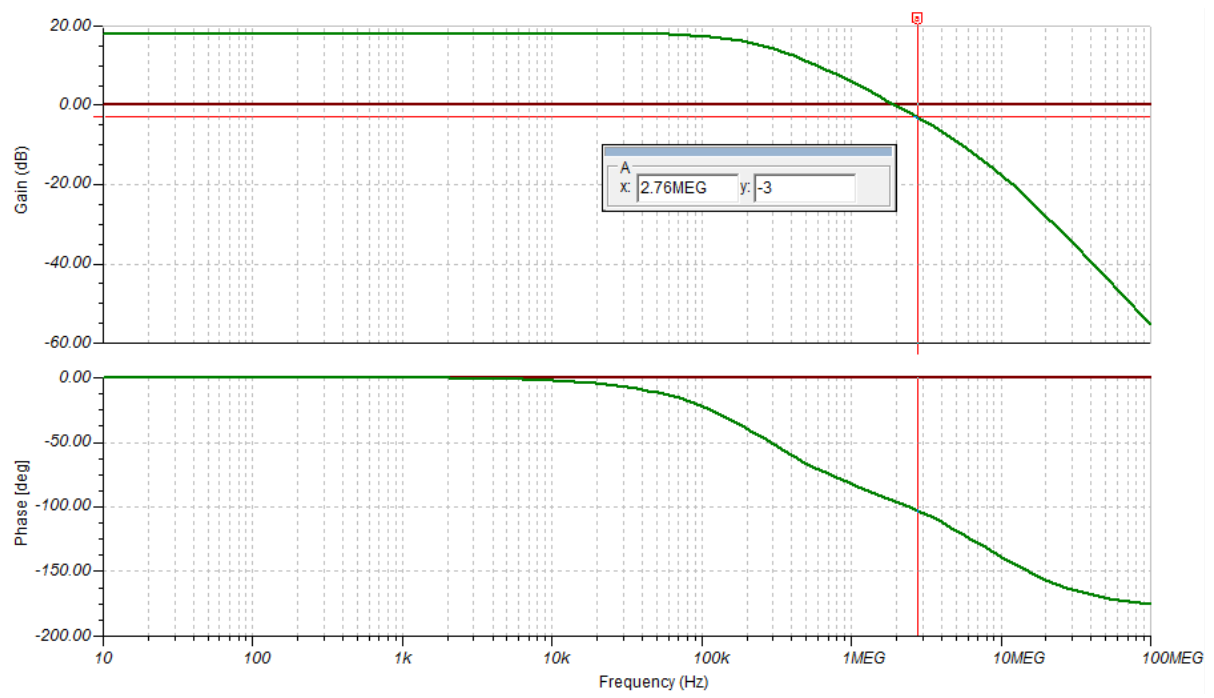

Fig. 10. $a c$ signal characteristic of AGC circuit using LM13700 in TINA-TI SPICE® simulation software

\subsection{Printed Circuit Board (PCB)}

A photograph of printed circuit board (PCB) of analog front-end receiver circuit is shown in Fig. 11. This circuit is designed by referencing into circuit on Fig. 4. Each stage of circuit is printed on the separate PCB, so that the stage of circuit can be used as needed. In each kit, there are three channel input for the voltage supply of $+5 \mathrm{~V}_{\mathrm{DC}}$, ground, and $-5 \mathrm{~V}_{\mathrm{DC}}$. For the channel input and output, there are 5 channel: $+5 \mathrm{~V}_{\mathrm{DC}}$, ground, $-5 \mathrm{~V}_{\mathrm{DC}}$, data and ground. The analog circuit kit is fabricated in a double layer PCB using yellow masking with discrete component. Besides that, the author also fabricated SOIC8 to DIP adapter for IC OPA 695 and OPA 847, to ease the IC substitution if it is defected. The ADC input board of this system is using BNC based connector, so we also developed the converter for female BNC. The standar impedances of this connector cable is $50 \Omega$, so the impedance matching circuit is needed. 


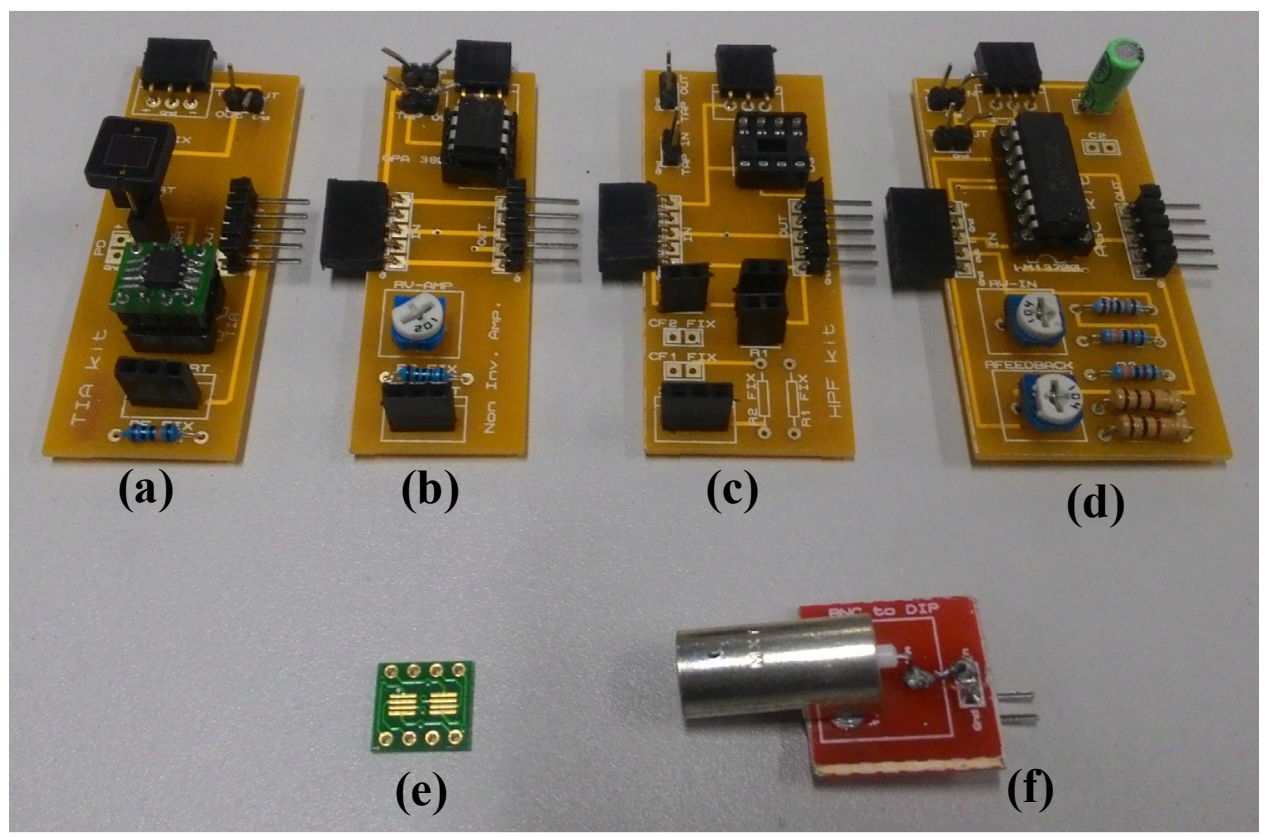

Fig. 11.The PCB design of proposed analog front-end receiver: (a) TIA kit with $23.30 \mathrm{~mm} \mathrm{x}$ $62.65 \mathrm{~mm}$; (b) non-inverting amplifier with $21.50 \mathrm{~mm} \times 62.65 \mathrm{~mm}$; (c) Sallen- key high pass filter as static interference noise filtering system with $26.75 \mathrm{~mm} \times 62.65 \mathrm{~mm}$; (d) AGC using LM13700 with $32.25 \mathrm{~mm} \times 62.65 \mathrm{~mm}$; (e) SOIC8 to DIP8 converter; (f) $\mathrm{BNC}$ female connector.

\section{Conclusion}

An analog front-end receiver of VLC system has been designed and has been tested using simulation based approach using TINA-TI SPICE® software. The proposed circuit of analog front-end receiver is consisted of: 1) trans-impedance amplifier which has $1.78 \mathrm{MHz}$ cut-off frequency, 2) analog-filter using high pass filter Sallenkey topology which able to pass signal above $51 \mathrm{KHz}$ and attenuate the signal under $50 \mathrm{KHz}$, and 3) AGC which utilized available commercially ICs, LM13700 from Texas Instrument, to provide stable output signal and has $2.76 \mathrm{MHz}$ bandwidth. The varying distance between LED-PD can produce fluctuated output signal. The proposed design is able to maintain stable output signal at $4 \mathrm{~V}_{\mathrm{DC}}$. Therefore, the proposed circuit design based on simulation is able to give a mobility feature for the VLC system. Next research, we will test the circuit based on real laboratory experiment, so that we will be able to provide the comparisons results of the real experiment with the simulation data, which is also interesting to be shown in the later publication. BER and SNR analysis and evaluation about filter and AGC circuit also will be included in our next research. The potential of this application is widely opened. The analog-front 
Paper-A First Approach to Design Mobility Function and Noise Filter in VLC System Utilizing Low...

end of this system can be minimized in size by using SMD component then implemented on the commercial mobile phone.

\section{Acknowledgment}

The authors wish to acknowledge the "Pusat Unggulan IPTEK Indonesia" and also administrator at the IC design laboratory, Institut Teknologi Bandung (ITB) for their financial support.

\section{References}

[1] Y. Hong and L-K Chen, "On the Performance of Mobile Visible Light Communications," [Online] Available at: https://arxiv.org/abs/1605.01848.

[2] C. H. Yeh, Y. L. Liu, C.W. Chow, "Real-time white-light phosphor-LED visible light communication (VLC) with compact size," Optic Express, Vol. 21(22), November 2013. https://doi.org/10.1364/OE.21.026192

[3] C. Henn, "Automatic Gain Control (AGC) using the Diamond Transistor OPA660," BurrBrown Application bulletin, pp. 1-10, October 1993

[4] S. Deng, E. Cleary, M.AP McAuliffe, L. Lewis, "Design of an auto-gain control transimpedance amplifier for optical sensing applications," Proc. of the $27^{\text {th }}$ Irish Signal and Systems Conf. (ISCC), June 2016.

[5] W. Han, S. Wang and Bo Yang, "Design and Implementation of AGC Algorithm Circuit for High PAPR Signal," Proc. of the 2016 IEEE Int. Conf. on Integrated Circuits and Microsystems, pp. 7-10, January 2017.

[6] T. Adiono, A. Pradana, R.V.W. Putra, S. Fuada, “Analog Filters Design in VLC Analog Front-End Receiver for Reducing Indoor Ambient Light Noise," Proc. of the IEEE Asia Pacific Conf. on Circuit and Systems (APCCAS), pp. 581-584, October 2016. https://doi.org/10.1109/APCCAS.2016.7804058

[7] C.H. Yeh, et al, "Simple digital FIR equalizer design for improving the phosphor LED modulation bandwidth in visible light communication," Opt. Quant. Electron, Vol. 45, pp. 901-905, 2013. https://doi.org/10.1007/s11082-013-9690-4

[8] W. Song, S. Dong, Z. Jia, "The Design and Realization of APD Receiving Circuit Used in M-ary VLC" Proc. of the 2015 IEEE 4th Global Conf. on Consumer Elect. (GCCE), pp. 543-544, October 2015.

[9] Y. Zhao, J. Vongkulbhisal, "Design of Visible Light Communication Receiver for On-Off Keying Modulation by Adaptive Minimum-Voltage Cancelation," Engineering J., Vol. 14(3), pp. 125-129, 2013. https://doi.org/10.4186/ej.2013.17.4.125

[10] L. Grobe, et al., "The Impact of Highpass Filtering when using PAM-FDE for Visible Light Communication," Proc. of the 2016 IEEE Wireless Commun. And Netw. Conf. Workshops (WCNCW), April 2016. https://doi.org/10.1109/WCNCW.2016.7552706

[11] S. Fuada, A.P. Putra, T. Adiono. Analysis of Received Power Characteristics of Commercial Photodiodes in Indoor LOS Channel Visible Light Communication. Unpublished.

[12] S. Fuada, T. Adiono, "Pengaruh Junction Capacitor $\left(\mathrm{C}_{\mathrm{j}}\right)$ Photodiode terhadap Noise pada TIA untuk Aplikasi Visible Light Communications (VLC)," unpublished.

[13] S. Fuada, A.P. Putra, Y. Aska, T. Adiono, "Short-range Audio Transfer through 3 Watt White LED based on LOS channels," Unpublished.

[14] J-H. Li, et. al., "An integrated PIN-array receiver for visible light communication," IOP Publishing J. Opt. 17 (105805), pp. 1-5, 2015. https://doi.org/10.1088/2040-8978/17/10/ $\underline{105805}$ 
Paper-A First Approach to Design Mobility Function and Noise Filter in VLC System Utilizing Low...

[15] Lih Chieh Png et. al,"MIMO-Diversity Switching Techniques for Digital Transmission in Visible Light Communication," Proc. of IEEE Symposium on Computers and Communications (ISCC), March 2014, https://doi.org/10.1109/ISCC.2013.6755008

[16] R. Mulyawan, "MIMO Visible Light Communications Using a Wide Field-of-View Fluorescent Concentrator," IEEE Photonics Technology Letters, Vol. 29(3), February 2017. https://doi.org/10.1109/LPT.2016.2647717

[17] P. Cherntanomwong, W. Chantharasena, "Indoor Localization System Using Visible Light Communication," Proc. of the $7^{\text {th }}$ Int. Conf. on Information Technology and Electrical Engineering (ICITEE), pp. 480-483, February 2016.

[18] L. Wei, H. Zhang, J. Song, "Experimental Demonstration of a Cubic-Receiver-Based MIMO Visible Light Communication System,” IEEE Photonics J., 7900107, Vol. 9(1), February 2017.

[19] A. P. Putra, S. Fuada, Y. Aska, T. Adiono, "System-on-Chip Architecture for High-Speed Data Acquisition in Visible Light Communication System," Proc. of the IEEE Int. Symposium on Electronics and Smart Devices (ISESD), October 2016. https://doi.org/10.1109/ isesd.2016.7886693

[20] T. Adiono, Yulian Y. Aska, A.A. Purwita, S. Fuada, A.P. Putra, "Modeling OFDM system with Viterbi Decoder Based Visible Light Communication," Proc. of the Int. Conf. on Electronic, Information and Communication (ICEIC), January 2017.

[21] T. Adiono, S. Fuada, A.P. Putra, Y. Aska, "Desain Awal Analog Front-End Optical Transceiver untuk aplikasi Visible Light Communication," J. Nasional Teknik Elektro dan Teknologi Informasi (JNTETI), Vol. 5(4), pp. 319-327, November 2016. https://doi.org/10.22146/jnteti.v5i4.280

[22] S. Fuada, T. Adiono, A. P. Putra, Y. Aska, "A Low-cost Analog Front-End (AFE) Transmitter Designs for OFDM Visible Light Communications," Proc. of the IEEE Int. Symposium on Electronics and Smart Devices (ISESD), October 2016.

[23] S. Fuada, T. Adiono, A. P. Putra, Y. Aska, "LED Driver Design for Indoor Lighting and Low-rate Data Transmission Purpose," Unpublished.

[24] L. Orozco, "Optimizing Precision Photodiode Sensor Circuit Design," Application note MS-2624, pp. 1-5, 2014. [Online] Available in http://www.analog.com/media/en/technicaldocumentation/technical-articles/Optimizing-Precision-Photodiode-Sensor-Circuit-DesignMS-2624.pdf.

[25] "Photodiode tutorial," [Online] Available at: https://www.thorlabs.com/tutorials.cfm ?tabID $=31760$,

[26] S. Fuada, A. P. Putra, Y. Aska, T. Adiono, "Trans-impedance Amplifier (TIA) Design for Visible Light Communication (VLC) using Commercially Available OP AMP," Proc. of $20163^{\text {rd }}$ Int. Conf. on Information Tech., Computer, and Electrical Engineering (ICITACEE), pp. 31-35, October 2016.

[27] T. Adiono, R.V.W. Putra, S. Fuada, "Noise and Bandwidth Considerations in Designing Op-Amp Based Transimpedance Amplifier for VLC," Unpublished

[28] S. Fuada, T. Adiono, Y. Aska, A.P. Putra, "Noise Analysis in VLC Optical Link based Discrette OP-AMP Trans-Impedance Amplifier (TIA)," Unpublished.

[29] S. Fuada, A.P. Putra, Y. Aska, T. Adiono, "Noise Analysis of Trans-impedance Amplifier (TIA) in Variety Op Amp for use in Visible Light Communication (VLC) System," Unpublished.

[30] K. Puntsri, E. Khansalee, P. Khophon and P. Siripakdee, "Experimental of realtime transmitter PAM-4 for optical wireless communication systems," Proc. of the $13^{\text {th }}$ Int. Conf. on ECTI-CON, September 2016. https://doi.org/10.1109/ECTICon.2016.7561343

[31] Z. Ghassemlooy, W. Popoola, S. Rajbhandari, "Optical Wireless and Communciations: System and Channel Modelling with Matlab ${ }^{\circledR}$," New york: CRC Express Taylor and Francis Group, 2012. 
Paper-A First Approach to Design Mobility Function and Noise Filter in VLC System Utilizing Low...

[32] A. Böcker, et al., "An implementation of a visible light communication system based on LEDs," Bachelor thesis, Chalmers University of Technology-Gothenburg, Sweden, 2015.

[33] A. Pradana, "Rancang Bangun Layer Fisik Komunikasi Cahaya Tampak Berbasis DCOFDM dan PWM,” Master Thesis, Institut Teknologi Bandung, Indonesia, 2016.

[34] G. Feng, et al., "The Design of AGC Circuit Based On the Variable Gain Amplifier AD603," Proc. of 5th Int. Conf. on Advanced Design and Manufacturing Engineering, pp. 2004-2007, January 2015. https://doi.org/10.2991/icadme-15.2015.371

[35] Datasheet, "LM13700 Dual Operational Transconductance Amplifiers With Linearizing Diodes and Buffers," Texas Instruments, November 2015.

\section{$7 \quad$ Authors}

Syifaul Fuada received B.Ed degree on Electrical Engineering Education major from State University of Malang (UM), Indonesia in 2014. Now he is working at Microelectronics Center Institut Teknologi Bandung. He holds two pending patents (helmet charger based solar energy and out-pipe inspection system based mobile robot) and several achievements such as, the best poster in SPRINT 2014, one of the 106 Indonesian Innovators by BIC-RISTEK DIKTI in 2014, the best poster in KIPNAS XI in 2015, student travel grant in IEEE APCCAS 2016, and one of 108 Indonesian Innovators by BIC in 2016. His research interests include: Analog circuits design, instrumentation system, circuit simulation, engineering education, multimedia learning, and visible light communication.

Angga Pratama Putra received his B.Sc. degree on Electrical Engineering from Institut Teknologi Bandung (ITB), Indonesia in 2015. He is currently Master Student majoring in Electrical Engineering with specialization in Computer Engineering, also in ITB. His research interests includes: Embedded System, VLSI, System-on-Chip, Internet of Things, Digital Signal Processing (DSP) and Visible Light Communication (VLC).

Yulian Aska, received his B.Sc. degree on Electrical Engineering from Institut Teknologi Bandung (ITB), Indonesia in 2014. Now, she is a yunior researcher member in Microelecronic Center ITB (Control system laboratory and IC design laboratory). Her research interests include, control system \& automation, VLSI, System-onChip, Digital Signal Processing (DSP) and visible light communication (VLC).

Trio Adiono obtained his Ph.D. degree in VLSI Design from Tokyo Institute of Technology, Japan, in 2002. He received the "Second Japan Intellectual Property Award" in 2000 from Nikkei BP for his research on "Low Bit-rate Video Communication LSI Design". He also holds a Japanese Patent on "High Quality Video Compression System". Currently, he is a lecturer at the School of Electrical Engineering and Informatics, a Head of the Microelectronics Center and IC Design Laboratory, ITB. He currently serves as a chair of the IEEE SSCS Indonesia Chapter. His research interests include VLSI, Signal and Image Processing, Visible Light Communication (VLC), Smart Card, Electronics Solution Design and Integration.

Article submitted 26 January 2017. Published as resubmitted by the authors 05 June 2017. 